\title{
Bond strength comparison of color-change adhesives for orthodontic bonding using a self-etching primer
}

This article was published in the following Dove Press journal:

Clinical, Cosmetic and Investigational Dentistry

30 June 2011

Number of times this article has been viewed

\section{Sara Ekhlassi \\ Jeryl D English \\ Joe C Ontiveros \\ John M Powers \\ Harry I Bussa \\ Gary N Frey \\ Clark D Colville \\ Randy K Ellis}

Houston Department of

Orthodontics, The University of Texas

Dental Branch, Houston, TX, USA
Correspondence: Sara Ekhlassi

6516 M. D. Anderson Blvd, Suite \#372,

Houston, TX 77030, USA

$\mathrm{Tel}+\mathrm{I} 7135004127$

Fax + I 713500 4123

Email saraekh@yahoo.com
Background: The purpose of this study was to compare the shear bond strengths of two color-change adhesives with a commonly used conventional light-cure adhesive while using a self-etching primer, and to compare any changes in shear bond strengths over time.

Methods: One hundred and eighty extracted bovine incisors were randomly divided into nine groups of 20 teeth each. The teeth were prepared with a self-etching primer (Transbond ${ }^{\mathrm{TM}}$ Plus) Metal lower incisor brackets were bonded directly to each tooth with two different colorchange adhesives (TransbondPlus and Grēngloo ${ }^{\mathrm{TM}}$ ) and a control (Transbond XT). The teeth were debonded at three different time points (15 minutes, 24 hours, 1 week) using an Instron at $1.0 \mathrm{~mm} / \mathrm{min}$. The teeth that were to be debonded at 24 hours and 1 week were stored in distilled water at $37^{\circ} \mathrm{C}$ to simulate the oral environment. The data were analyzed by two-way analysis of variance and with Fisher's protected least-significant difference multiple comparisons test at the $P<0.05$ level of significance. Adhesive remnant index (ARI) scores were calculated for each debonded tooth.

Results: Transbond Plus at 1 week had the highest mean shear bond strength $(14.7 \mathrm{mPa})$. Grēngloo tested at 24 hours had the lowest mean shear bond strength $(11.3 \mathrm{mPa})$. The mean shear bond strengths for the remaining seven groups had a range of $12-14.5 \mathrm{mPa}$. Grengloo had $>80 \%$ samples presenting with an ARI score of 1 at all times. Interestingly, both Transbond groups had ARI scores of 3 in more than $50 \%$ of their samples.

Conclusion: Time had no significant effect on the mean shear bond strength of Transbond XT, Grengloo, or Transbond Plus adhesive.

Keywords: bond strength, color-change adhesives, self-etching primer, orthodontic bonding

\section{Introduction}

With the invention of bonding of orthodontic brackets to enamel over 30 years ago, orthodontics as a specialty has changed dramatically. ${ }^{1}$ Prior to the introduction of the acid-etch bonding technique by Buonocore, every tooth was banded in preparation for orthodontic treatment. The ability to bond orthodontic brackets has reduced patient chair time, reduced band space that would need to be closed later, improved esthetics, and aided in improvement of hygiene. ${ }^{2}$ Today, with the introduction of newer bonding materials, orthodontics continues to evolve. In addition, the development of self-etching primers has further contributed to the ease of the bonding process. ${ }^{3}$ These primers eliminate the need to acid-etch the tooth surface prior to addition of the adhesive, thus reducing the number of steps involved in the bonding process.

Although ease of bonding has significantly improved due to direct bonding techniques and the availability of self-etching primers, the formation and prevalence of 
white spot lesions throughout orthodontic therapy continues to be a major area of concern for orthodontists. Decalcification of enamel and ensuing white spot lesions are common around orthodontic brackets. ${ }^{4}$ Gorelick et al found that $5 \%$ of patients undergoing fixed appliance therapy had at least one white spot lesion after treatment, irrespective of whether teeth were bonded or banded. ${ }^{5}$ These lesions can develop as early as 1 month into treatment, ${ }^{6,7}$ and remain an esthetic concern 5 years after removal of the appliances. ${ }^{8,9}$ During the bonding process, it is not uncommon to leave excess bonding adhesive around bracket margins unknowingly. This problem is exacerbated by the fact that many bonding adhesives are similar in shade to enamel in order to improve esthetics, but make identification of adhesive remnants more difficult. ${ }^{10,11}$

After completion of orthodontic treatment, a primary consideration is to return the enamel to its original state. During debonding it can be difficult to delineate the enameladhesive interface, causing potential enamel loss and/or damage during its removal. Many studies have investigated the amount of enamel loss after debonding, with results in the range of 5-150 $\mu \mathrm{m} .{ }^{11-14}$

Various orthodontic companies have manufactured color-changing adhesives to help remove excess adhesive before light-curing during bonding and after debonding. Transbond ${ }^{\mathrm{TM}}$ Plus is a color-change orthodontic bonding adhesive manufactured by $3 \mathrm{M}$ Unitek (Monrovia, CA) which claims excellent bond strength of the adhesive with both metal and ceramic brackets. ${ }^{15}$

The pink indicator incorporated in Transbond Plus becomes activated when it is exposed to light, both with ambient light and through curing. The color change of the adhesive is not an indication of a complete cure or polymerization, but rather facilitates acceptable esthetics during the course of treatment. ${ }^{15}$ The initial pink color is intended to facilitate removal of excess adhesive flash during bracket bonding (prior to curing) that can become a potential site of bacterial colonization and lead to enamel decalcification. ${ }^{16-18}$ Furthermore, remaining adhesive can also act as a mechanical irritant to the gingiva. ${ }^{17}$

Blugloo ${ }^{\mathrm{TM}}$ is a dual color-change adhesive developed by Ormco Corporation (Glendora, CA) which claims an optimized formulation for esthetic brackets. At cooler temperatures the adhesive possesses a blue color, which then changes to a translucent color when the adhesive increases to warmer body temperatures. This color-change property allows for removal of excess adhesive during bracket placement and identifiable cleanup of the adhesive remnants after debonding once the adhesive is cooled with air or water. ${ }^{19}$ Grengloo ${ }^{\mathrm{TM}}$ (Ormco Corporation) is a similar dual color-change adhesive manufactured specifically for metal brackets. According to the Ormco website, ${ }^{20}$ Grengloo polymerizes faster than other light-cured orthodontic bonding adhesives, providing a higher proportion of total bond strength at initial force loading. It is also designed to have up to $118 \%$ greater impact resistance for reducing bond failures from traumatic impact. Its patented chemical formula has an affinity for metal brackets which helps to ensure reliable bond strength. The green color of the adhesive at lower temperatures during bonding facilitates the removal of excess adhesive. As the adhesive warms to body temperature, the color disappears, remaining clear throughout treatment. After debonding, a short blast of cool air or water is enough to lower the surface temperature and return the adhesive to its original green color for easy removal of adhesive remnants. ${ }^{20}$

A study by Duers et al compared the bond strengths of different color-change adhesives (Transbond Plus, Blugloo, and Grengloo) relative to a conventional light cure adhesive (Transbond XT) used for orthodontic bonding. The study used $35 \%$ phosphoric acid etch and traditional primer to prepare the tooth surface prior to the addition of the adhesive and orthodontic bracket. Although the average shear bond strengths varied among the adhesives at two time points ( 15 minutes and 24 hours after bonding), all measurements were still within the recommended bond strength range for orthodontic bonding. ${ }^{21}$ As trends towards using self-etching primers increase in the field of orthodontics, it is important to evaluate the bond strengths of color-change adhesives when used in conjunction with a self-etching primer. Furthermore, it is important to investigate the longevity of these adhesives after bonding.

The introduction of new materials that are capable of helping clinicians to achieve better results has always been intriguing. The addition of color-changing adhesives to orthodontic bonding is very promising, and therefore an evaluation of their bond strength is required to gain knowledge of their clinical success. The purpose of this study was to compare the bond strength of two different color-change adhesives formulated for optimal use with metal brackets. The color-change adhesives were compared with a conventional light-cure adhesive while using a self-etching primer. The conditions were tested at 15 minutes, 24 hours, and 1 week in order to investigate longevity.

\section{Methods and materials}

One hundred and eighty extracted bovine incisors (Animal Technologies Inc, Tyler, TX) were obtained. These 
incisors were previously mounted in acrylic resin cylinders (SamplKwick ${ }^{\circledR}$ fast-cure acrylic resin, Buehler Ltd, Lake Bluff, IL). The roots of the incisors were shortened with a slow-speed diamond saw to facilitate mounting. Exposed facial surfaces of the enamel were ground using an Ecomet $6^{\circledR}$ variable speed grinder-polisher (Buehler Ltd) to obtain an appropriate surface area for bonding of the orthodontic brackets.

Prior to bonding, the teeth were randomly divided into three groups of 60 specimens each. Each group represented one of the three light-cured orthodontic bonding adhesives to be tested, ie, Transbond Plus, Grengloo, and Transbond XT. Transbond Plus and Grengloo were the color-change light-cured adhesives, while Transbond XT was the conventional light-cured adhesive used as a control. Each of the three adhesive groups were then further divided into three subgroups of 20 specimens each, for a total of nine subgroups. The subgroups represented the three different time points to be tested, ie, 15 minutes, 24 hours, and 1 week.

Prior to bonding, the exposed enamel of each specimen was rinsed and thoroughly air-dried. The primer used was Transbond Plus self-etching primer (3M Unitek). The manufacturer's instructions were followed to ensure proper use of the self-etching primer. The three wells were properly and thoroughly mixed. The final mixture was checked for a light yellow color to confirm proper mixing. The tip of the applicator was dipped into the mixture and rubbed onto each tooth for 5 seconds while applying some pressure. A gentle air burst for 1-2 seconds was applied to each tooth to dry the primer into a thin film. The applicator was redipped into the reservoir to saturate the tip prior to rubbing it onto the next specimen. The orthodontic adhesive being tested was placed on the bracket base (3M Unitek Victory Series ${ }^{\mathrm{TM}}$ Low Profile 0.022 mandibular incisor brackets). The bracket was then seated and positioned on the bovine teeth, after which excess adhesive was removed using a scaler. The adhesive was then light-cured for 5 seconds on each side of the bracket base (mesial, distal, incisal, gingival) for a total of 20 seconds per tooth. The light curing unit was an Ortholux LED (3M Unitek). All specimens were bonded by the same operator.

All specimens were then tested under shear load using a universal Instron testing machine (Model 4454; Instron Corporation, Canton, MA) at a crosshead rate of $1.0 \mathrm{~mm} / \mathrm{minute}$. The subgroups that were to be debonded at 24 hours and at 1 week were placed in containers with distilled water and stored at $37^{\circ} \mathrm{C}$ to simulate the oral environment prior to testing. Mean values in $\mathrm{mPa}$ and standard deviations of bond strengths were calculated. The data were analyzed using two-way analysis of variance and with Fisher's protected least-significant difference multiple comparisons test at the 0.05 level of significance.

After debonding, each specimen was evaluated for its adhesive remnant index (ARI). The ARI was developed by Artun and Bergland ${ }^{22}$ in 1984 as a four-point scale to assess the amount of adhesive remaining on the tooth surface after debonding. An ARI of 0 signifies $0 \%$ of adhesive remaining on the tooth, ARI 1 signifies $\leq 50 \%$ of adhesive remaining on the tooth, ARI 2 signifies $>50 \%$ of adhesive remaining on the tooth, and ARI 3 signifies $100 \%$ of adhesive remaining on the tooth with a distinct impression of the bracket mesh pad. Each specimen was examined by one operator under $3.5 \times$ magnification.

\section{Results}

Sixty teeth were bonded using each orthodontic bonding adhesive for a total sample size of 180 teeth. Each adhesive group was subdivided into three groups to test three debonding times of 15 minutes, 24 hours, and 1 week. Transbond Plus at 1 week had the highest mean shear bond strength at $14.7 \mathrm{mPa}$, Grengloo tested at 24 hours had the lowest mean shear bond strength of $11.3 \mathrm{mPa}$, and the mean shear bond strengths for the remaining seven groups had a range of 12.0-14.5 mPa (Table 1).

Overall, there were no significant differences in shear bond strength for the main effects of time, ie, 15 minutes, 24 hours, and 1 week $(P=0.43$, Table 2$)$. However, there were significantly different effects in shear bond strength among the adhesives $(P=0.04)$. More than $80 \%$ of Grengloo samples presented with an ARI score of 1 at all times. Fewer samples from Grengloo had ARI scores of 2 and 3, but none presented with a score of 0 . Interestingly, both Transbond groups had $>50 \%$ of samples with ARI scores of 3. Twenty-five percent of the Transbond XT samples had an ARI of score of 0 only at 24 hours, which may indicate potential enamel damage at the time of debonding (Table 3 ).

Table I Mean bond strengths (mPA) of three adhesives with respect to time

\begin{tabular}{|c|c|c|c|}
\hline Adhesive & 15 minutes & 24 hours & I week \\
\hline Transbond $^{\mathrm{TM}} \mathrm{XT}$ & $14.4(3.7)$ & I3.7 (3.8) & I $3.5(5.2)$ \\
\hline Grēngloo ${ }^{T M}$ & $12.0(5.9)$ & I I.3 (2.8) & I $4.3(5.1)$ \\
\hline Transbond Plus & | $4.3(4.0)$ & $14.5(2.8)$ & | 4.7 (4.3) \\
\hline
\end{tabular}

Note: *Standard deviations are shown in parentheses. 
Table 2 Analysis of variance table for bond strength

\begin{tabular}{llll}
\hline & F value & P-value & Power \\
\hline Time & 0.83 & 0.43 & 0.18 \\
Adhesive & 3.08 & 0.04 & 0.58 \\
Time-adhesive interaction & 1.08 & 0.36 & 0.32 \\
\hline
\end{tabular}

\section{Discussion}

Since the development of direct orthodontic bonding, various new developments have been made to help improve the technique. These developments have focused on improving bond strength, decreasing bonding time, reducing the number of bonding steps, and decreasing adhesive remnants. All these advances have worked towards creating the most efficient bonding protocol while maintaining enamel health during treatment and after debonding. As newer and more efficient products are marketed, we must also evaluate their interactions with other orthodontic products available to practitioners, as well as their effects on enamel.

This study compared shear bond strengths of two colorchange adhesives (Transbond Plus and Grengloo) with a conventional light-cured adhesive (Transbond XT) when using a self-etching primer (Transbond Plus self-etching primer). The shear bond strengths were measured at 15 minutes, at 24 hours, and at 1 week after bonding. Many adhesives completely polymerize in 24 hours. Therefore, these three time periods were specifically included to compare the immediate, 24-hour, and slightly longer follow-up stages.

Previous research has compared the bonding characteristics and strengths of human enamel and bovine enamel. The results of these studies have indicated similar physical properties, composition, and bond strength between human and bovine enamel. It has been concluded that bovine enamel is an adequate substitute for human enamel..$^{23-26}$ Therefore, it was decided to use bovine enamel in this study.

Table 3 Adhesive remnant index scores for adhesives for all time points

\begin{tabular}{|c|c|c|c|c|c|c|}
\hline \multirow[b]{2}{*}{ Storage interval } & \multicolumn{6}{|c|}{ ARI score } \\
\hline & Bonding agent & 0 & I & 2 & 3 & Total (n) \\
\hline \multirow[t]{3}{*}{15 minutes } & Transbond $^{\mathrm{TM}} \mathrm{XT}$ & 0 & 5 & 4 & 11 & 20 \\
\hline & Transbond Plus & I & 0 & 6 & 13 & 20 \\
\hline & Grēngloo ${ }^{\mathrm{TM}}$ & 0 & 16 & 2 & 2 & 20 \\
\hline \multirow[t]{3}{*}{24 hours } & Transbond XT & 5 & 11 & 2 & 2 & 20 \\
\hline & Transbond Plus & 0 & 2 & 3 & 15 & 20 \\
\hline & Grēngloo & 0 & 20 & 0 & 0 & 20 \\
\hline \multirow[t]{3}{*}{ I week } & Transbond XT & I & 6 & 3 & 10 & 20 \\
\hline & Transbond Plus & 0 & 2 & 3 & 15 & 20 \\
\hline & Grēngloo & 0 & 17 & 2 & I & 20 \\
\hline
\end{tabular}

Abbreviation: ARI, adhesive remnant index.
Time had no statistically significant effect on the bond strengths of the adhesives. It is important to note that the bond strengths of all the adhesives after bonding with Transbond Plus self-etching primer ranged from $11.3 \mathrm{mPa}$ to $14.7 \mathrm{mPa}$. These values were higher than the $6-8 \mathrm{mPa}$ previously reported as an adequate bond strength for routine orthodontic treatment. ${ }^{27}$ Higher bond strengths can mean a greater risk of enamel fracture upon debonding. Of the three adhesives tested, Grengloo had slightly lower bond strength when used with a self-etching primer.

This difference in mean shear bond strength may be attributed to differences in material composition. Transbond XT mostly contains silane-treated quartz particles, with smaller amounts of bisphenol, a diglycidyl ether dimethacrylate (bisGMA) and bisphenol-A bis (2-hydroxyethyl ether) dimethacrylate. Transbond PLUS has similar ingredients, including silane-treated quartz and bisGMA, although to a smaller extent. Half of the filler content of Transbond Plus is glass-reacted with hydrolyzed silane. Grengloo, on the other hand, is made of inert fillers and pigments, with very small additions of glycidyl methacrylate and phenylbis (2,4,6-trimethylbenzoyl)-phenylphosphine oxide. Therefore, the similarity in shear bond strength of Transbond XT and Transbond Plus over time may be explained by the similar components of these materials.

In orthodontics, the location of bond failure is significant because an effort is made to maintain a sound and intact enamel surface posttreatment. Thus, in order to minimize the risk of enamel fracture, it is more desirable for bond failure to occur at the bracket-adhesive interface or within the adhesive than at the adhesive-enamel junction. However, a smaller adhesive remnant can mean less chair time for removal of the adhesive remaining after debonding. The ideal bonding system would leave a healthy enamel surface without large amounts of adhesive to remove.

When evaluating the ARI scores of the three adhesives, Grengloo bonded with self-etching primer demonstrated a similar trend for all three time periods. Less than $50 \%$ of the remnant adhesive was observed on the tooth surface in $>80 \%$ of the samples. Furthermore, none of the samples had any adhesive left on the tooth surface. This may be because of the ideal property of the material as there was no indication of potential enamel fracture.

Transbond XT, Transbond Plus, and Grengloo all had higher shear bond strengths than necessary for routine orthodontic treatment when used in combination with Transbond Plus self-etching primer. Interestingly, a study by Türkkahraman et $\mathrm{al}^{28}$ yielded similar findings. Their results 
indicated no significant difference in mean shear bond strength between the Transbond Plus and Grengloo adhesives. Furthermore, according to our results, their mean shear bond strength values are also very close to each other, and are well above the suggested range of shear strength in orthodontics. The main difference between these adhesives is the colorchange characteristics of Transbond Plus and Grengloo. Both color-change adhesives facilitate excess adhesive removal at bonding and decrease the risk of enamel decalcification and white spot lesions. However, Grenglooalso has the ability to return to its initial green color after debonding when exposed to cooler temperatures. These properties can help clinicians delineate what areas are adhesive remnants needing removal and what areas are enamel.

Shear bonding tests involve numerous variables and are technique-sensitive, so the same bonding study can have varying results under different experimental conditions or when performed by different operators. An in vitro bonding environment is very different from an in vivo bonding environment. Factors such as saliva contamination and the patient's enamel composition can cause the same bonding study to yield different results when performed intraorally. Thus, it is important to follow through with more clinical studies. It may be of interest to test the color-change adhesives further by bonding them directly to the enamel surface (without a metal bracket). In this way, bond strength at the enamel-adhesive interface can be evaluated without the added variable of the bracketadhesive interface.

\section{Conclusion}

Time had no significant interaction in this comparison of mean shear bond strength forTransbond XT, Grengloo, and Transbond Plus adhesives. Although there was a significant difference in the mean shear bond strength for the three groups, all three adhesives demonstrated adequate bond strength to withstand orthodontic forces throughout the experiment.

\section{Acknowledgments}

Thanks are extended to the University of Texas Dental Branch at Houston Department of Orthodontics for their support with this project, to Neil Raney for his help in data collection, and to The Texas Orthodontic Foundation for their financial support.

\section{Disclosure}

The authors report no conflicts of interest in this work.

\section{References}

1. Newman GV, Snyder WH, Wilson CW. Acrylic adhesives for bonding attachments to tooth surfaces. Angle Orthod. 1968;38(1):12-18.

2. Buonocore MG. A simple method of increasing the adhesion of acrylic filling materials to enamel surfaces. J Dent Res. 1955;34(6):849-853.

3. Craig RG, Powers JM. Restorative Dental Materials.11th ed. St Louis, MO: CVMosbyInc; 2002.

4. Travess H, Roberts-Harry D, Sandy J. Orthodontics. Part 6: Risks in orthodontic treatment. Br Dent J. 2004;196(2):71-77.

5. Gorelick L, Geiger AM, Gwinnett AJ. Incidence of white spot formation after banding and bonding. Am J Orthod. 1982;81(2):93-98.

6. O'Reilly MM, Featherstone JD. Demineralization and remineralization around orthodontic appliances: An in vivo study. Am J Orthod Dentofacial Orthop. 1987;92(1):33-40.

7. Øgaard B, Rolla G, Arends J. Orthodontic appliances and enamel demineralization. Part 1. Lesion development. Am J Orthod Dentofacial Orthop. 1988;94(1):68-73.

8. Artun J, Thylstrup A. A 3-year clinical and SEM study of surface changes of carious enamel lesions after inactivation. Am J Orthod Dentofacial Orthop. 1989;95(4):327-333.

9. Øgaard B. Prevalence of white spot lesions in 19 year olds: A study on untreated and orthodontically treated persons 5 years after treatment. Am J Orthod Dentofacial Orthop. 1989;96(5):423-427.

10. Caspersen I. Residual acrylic adhesive after removal of plastic orthodontic brackets: A scanning electron microscopic study. Am J Orthod. 1977;71(6):637-650.

11. Zachrisson BU, Arthun J. Enamel surface appearance after various debonding techniques. Am J Orthod. 1979;75(2):121-127.

12. Fitzpatrick DA, Way DC. The effects of wear, acid etching, and bond removal on human enamel. Am J Orthod. 1977;72(6):671-681.

13. Pus MD, Way DC. Enamel loss due to orthodontic bonding with filled and unfilled resins using various clean-up techniques. Am J Orthod. 1980;77(3):269-283.

14. Krell KV, Courey JM, Bishara SE. Orthodontic bracket removal using conventional and ultrasonic debonding techniques, enamel loss, and time requirements. Am J Orthod Dentofacial Orthop. 1993; 103(3):258-266.

15. 3M Unitek. Available at: http://solutions.3m.com/wps/portal/3M/en US/orthodontics/Unitek/solutions/adhesive/Transbond-color-change/. Accessed April 5, 2011.

16. Zachrisson BJ. A posttreatment evaluation of direct bonding in orthodontics. Am J Orthod. 1977;71(2):173-189.

17. Eliades T, Eliades G, Brantley WA. Microbial attachment on orthodontic appliances: I. Wettability and early pellicle formation on bracket materials. Am J Orthod Dentofacial Orthop. 1995;108(4):351-360.

18. Brennan JV, James D, Soo PP, Tzou S. The APC Plus adhesive coated appliance system: Features and technical review. Orthodontic Perspectives. 2004;11(1):5-9.

19. OrmcoSymbron Dental Specialties. Available at: http://www.ormcoeurope.com/?cid=287. Accessed April 5, 2011.

20. OrmcoSymbron Dental Specialties. Available at: http://www.ormco. com/index/ormco-products-grēngloo. Accessed April 5, 2011.

21. Duers MW. Bond strength comparison of color change adhesives for orthodontic bonding. MS Thesis, Department of Orthodontics, University of Texas Health Science Center Dental Branch at Houston, Houston, TX, 2009.

22. Artun J, Bergland S. Clinical trials with crystal growth conditioning as an alternative to acid-etch enamel pretreatment. Am J Orthod. 1984; 85(4):333-340.

23. Nakamichi I, Iwaku M, Fusayama T. Bovine teeth as possible substitutes in the adhesion test. J Dent Res. 1983;62(10):1076-1081.

24. Osterle LJ, Shellhart WC, Belanger GK. The use of bovine enamel in bonding studies. Am J OrthodDentofacialOrthop. 1998;114(5): 514-519.

25. Saleh F, Taymour N. Validity of using bovine teeth as a substitute for human counterparts in adhesive tests. East Mediterr Health J. 2003; 9(1-2):201-207. 
26. Reis AF, Giannini M, Kavaguchi A, Soares CJ, Line SR. Comparison of microtensile bond strength to enamel and dentin of human, bovine, and porcine teeth. J Adhes Dent. 2004;6(2):117-121.

27. Reynolds IR. A review of direct orthodontic bonding. $\mathrm{Br} J$ Orthod. 1975;2:171-178.
28. Türkkahraman H, Adanir N, Gungor AY, Alkis H. In vitro evaluation of shear bond strengths of colour change adhesives. Eur J Orthod. 2010;32(5):571-574.

\section{Publish your work in this journal}

Clinical, Cosmetic and Investigational Dentistry is an international, peer-reviewed, open access, online journal focusing on the latest clinical and experimental research in dentistry with specific emphasis on cosmetic interventions. Innovative developments in dental materials, techniques and devices that improve outcomes and patient satisfac- tion and preference will be highlighted. The manuscript management system is completely online and includes a very quick and fair peerreview system, which is all easy to use. Visit http://www.dovepress. com/testimonials.php to read real quotes from published authors.

Submit your manuscript here: http://www.dovepress.com/clinical-cosmetic-and-investigational-dentistry-journal 